\title{
Atratividade de proteína hidrolisada de milho em mistura com bórax sobre moscas-das-frutas (Diptera: Tephritidae) em gaiolões de campo
}

\author{
Attractiveness of corn steep liquor plus \\ borax to fruit fly (Diptera: Tephritidae) under field cages
}

Adalton Raga ${ }^{\text {* }}$, Stella Maria Januária Vieira ${ }^{1,2}$

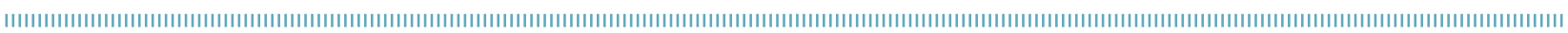

\begin{abstract}
RESUMO: Várias espécies de moscas-das-frutas (Diptera: Tephritidae) são capturadas em armadilhas contendo soluçóes aquosas preparadas com atrativos alimentares proteicos. Milhocina ${ }^{\circledR}$ é um produto hidrolisado de milho que apresenta um $\mathrm{pH}$ ácido. A adição de bórax pode aumentar o $\mathrm{pH}$ e melhorar a atratividade a tefritídeos adultos. Esta pesquisa objetivou avaliar a atratividade sob diferentes tempos de exposição de Milhocina ${ }^{\circledR}$ diluída a 5\% (v/v) em mistura com 4 , 7 e $10 \%$ de bórax, comparando-a com a proteína comercial padrão Bio Anastrepha a 3\% (v/v). Vinte casais de Ceratitis capitata com 2 a 3 dias de idade e 20 casais de Anastrepha fraterculus com 1 a 3 dias foram liberados no interior dos gaiolóes de $8,0 \mathrm{~m}^{3}$, no início de cada período de exposiçáo $(0-2,2-4,4$ - 7 e 7 - 10 dias $)$. No centro superior de cada gaioláo foi pendurada uma armadilha McPhail plástica transparente contendo $400 \mathrm{~mL}$ de solução atrativa. Ao final de cada período de exposição, os adultos capturados foram retirados, contados e sexados. Maior quantidade de adultos de C. capitata foi capturada no atrativo padrão Bio Anastrepha. Esse produto capturou mais fêmeas e machos de $A$. fraterculus do que os demais atrativos. Houve maiores capturas de machos e de fêmeas + machos de $C$. capitata do que de $A$. fraterculus nos tratamentos com Milhocina ${ }^{\circledR}$. Maiores capturas de fêmeas dos tefritídeos testados foram obtidas por Milhocina ${ }^{\circledR}+$ bórax $4 \%$ e por Bio Anastrepha até 7 dias de exposição dos atrativos. Em geral, no período de 2 4 dias de exposição houve um aumento da atratividade das soluçóes proteicas para fêmeas e machos de C. capitata e $A$. fraterculus.
\end{abstract}

PALAVRAS-CHAVE: Ceratitis capitata; Anastrepha fraterculus; monitoramento; armadilha McPhail.

\begin{abstract}
Several species of fruit flies (Diptera: Tephritidae) are captured by traps baited with liquid protein food attractants. Milhocina ${ }^{\circledR}$ is a hydrolysate of corn with acidic $\mathrm{pH}$. Addition of borax can increase the $\mathrm{pH}$ of the solution and improve the attractive performance for adult tephritids. The objective of this work was to evaluate the attractiveness under several times of exposure of $\left(\right.$ Milhocina $\left.^{\circledR}\right)$ at $5 \%(\mathrm{v} / \mathrm{v})$ by adding borax at 4,7 and $10 \%$ in comparison with the standard commercial protein at $3 \%$ $(\mathrm{v} / \mathrm{v})$ (BioAnastrepha). Twenty pairs of 2 to 3 years old of Ceratitis capitata and 20 pairs of 1 to 3 years old of Anastrepha fraterculus were released inside of field cage $\left(8.0 \mathrm{~m}^{3}\right)$ in the beginning of each exposure period $(0-2,2-4,4-7$ e $7-10$ days). In the upper surface of each field cage, a transparent plastic McPhail trap was kept with $400 \mathrm{~mL}$ of attractive. After each exposure time, the adults captured were counted and sexed. Greater amounts of $C$. capitata adults were captured in attractive standard Bio Anastrepha. This product captured more females and males of $A$. fraterculus than other attractants. There were higher catches of male and female + male $C$. capitata than $A$. fraterculus in treatments with Milhocina ${ }^{\circledR}$. More captures of females tested tephritids catches were obtained by Milhocina ${ }^{\circledR}+4 \%$ borax and Bio Anastrepha up to 7 days of exposure of the attractants. In general, during the period of $2-4$ days of exposure, there was an increase in the attractiveness of protein solutions for females and males of C. capitata and A. fraterculus.
\end{abstract}

KEYWORDS: Ceratitis capitata; Anastrepha fraterculus; monitoring; McPhail trap. 


\section{INTRODUÇÃO}

Moscas-das-frutas (Diptera: Tephritidae) são as mais importantes pragas da fruticultura mundial e o seu ataque provoca prejuízos quantitativos e restriçôes no comércio internacional de vegetais (RAGA et al., 2004). A mosca-do-mediterrâneo Ceratitis capitata (Wied.) e a mosca-da-fruta-sul-americana Anastrepha fraterculus (Wied.) são as mais importantes espécies de Tephritidae no Brasil (RAga et al., 2011).

$\mathrm{O}$ manejo racional e eficiente das moscas-das-frutas tem como pré-requisito o conhecimento do momento adequado para iniciar as medidas de controle. A eficácia dessas medidas depende em grande parte da disponibilidade de bons atrativos (NASCimento et al., 2000), tanto para a condução de sistemas de detecção e monitoramento como para o seu emprego em sistemas de controle (Salles, 1999). O monitoramento deve propiciar condiçóes de previsibilidade do risco de danos por determinada população de moscas-das-frutas (RAGA, 2005).

Adultos de moscas-das-frutas são atraídos por material proteico em decomposição, fato que viabiliza o monitoramento por meio de armadilhas contendo atrativos líquidos com maior teor de proteína. $\mathrm{O}$ uso de atrativos disponíveis no mercado internacional para armadilhas McPhail, como NuLure e Torula, é reduzido em países da América Latina (PIŃERo et al., 2003), em vista das limitaçóes causadas aos fruticultores, devido ao alto custo desses produtos e à falta de disponibilidade no mercado de suprimentos para monitoramento de pragas.

$\mathrm{O}$ atrativo alimentar líquido serve ao mesmo tempo como mecanismo de atração e de captura (Thomas et al., 2001). No entanto, adultos de moscas-das-frutas podem ser atraídos para a superfície externa das armadilhas McPhail e não ser capturados. Por isso, existe uma baixa captura de moscas-das-frutas a campo, como observado para Anastrepha ludens (Loew), A. obliqua (Macquart) e A. serpentina (Wied.) em mangueiras (Aluja et al., 1989). Essa baixa captura é influenciada também por fatores como composição e idade do atrativo, idade dos insetos e condiçóes ambientais (Aluja, 1994). Embora armadilhas McPhail e iscadas com compostos proteicos atraiam ambos os sexos de tefritideos, existe uma maior captura de fêmeas a campo (Malo, 1992; EpsKy et al., 1994).

No Brasil, melaço de cana-de-açúcar e sucos de frutas são atrativos empregados em muitas áreas frutícolas em detrimento de proteínas hidrolisadas, tanto para monitoramento como para o preparo de iscas tóxicas (Montes; RaGA, 2006). O nitrogênio amoniacal em sua forma gasosa é um dos principais compostos finais da decomposiçáo dos atrativos proteicos, sendo componente chave no poder atrativo de moscas-das-frutas (MAzor, 2009). A adição de bórax na soluçấo da proteína hidrolisada aumenta a vida útil do atrativo no campo (Lopez et al., 1971), devido ao aumento do $\mathrm{pH}$ inicial e consequente diminuição da velocidade de liberaçáo de amônia (HeAth et al., 2009).
Alguns atrativos comercializados no Brasil apresentam alto teor de melaço de cana-de-açúcar, o que em muitos casos tem comprometido a eficiência do manejo integrado, devido a falhas no adequado monitoramento de moscas-das-frutas (RAGA, 2005; RAGA et al., 2006). Além disso, compostos não adequados causam problemas de atração de espécies não alvos, incluindo insetos benéficos (RAGA et al., 2006; JANG et al., 2007; VILLAR et al., 2010).

Existem diferenças na capacidade de atração das proteínas disponíveis no mercado nacional, devido a diferenças na composição, tipo de formulação e estabilidade do produto (RAGA, 2005; RAGA et al., 2006). A fonte nitrogenada da maioria dos atrativos proteicos disponíveis no mercado brasileiro é proteína hidrolisada, subproduto originário da indústria de processamento de milho. O presente trabalho objetivou avaliar, em condiçôes de semicampo, a atratividade sob diferentes períodos de exposição da proteína hidrolisada em mistura com bórax, visando ao seu emprego no monitoramento de adultos de $C$. capitata e $A$. fraterculus.

\section{MATERIAL E MÉTODOS}

Os adultos utilizados nos testes foram obtidos das colônias de C. capitata e A. fraterculus, mantidas desde 1993 no Laboratório de Entomologia Econômica do Instituto Biológico (LEE/ CEIB), em Campinas, São Paulo. As larvas da mosca-do-mediterrâneo foram criadas em dieta artificial (RAGA et al., 1996) e as da mosca-da-fruta-sul-americana foram criadas em frutos de mamão papaia (RAGA et al., 1993). Nas gaiolas de emergência estavam disponíveis água e uma mistura de $1: 3 \mathrm{p} / \mathrm{p}$ de extrato de levedo e açúcar refinado para alimentação dos adultos. Duas horas antes das liberaçôes nos gaiolóes, as moscas foram mantidas em jejum.

O produto Milhocina ${ }^{\circledR}$ (proteína hidrolisada) foi diluído a 5\% (v/v) em água destilada acrescida da mistura com 4, 7 e $10 \%$ de bórax (tetraborato de sódio), marca PlantBoro 11, e comparado com a proteína comercial padrão Bio Anastrepha $3 \%(\mathrm{v} / \mathrm{v})$.

Os gaiolóes de formato cúbico foram confeccionados em cano de PVC e cobertos com tela antiafídeo; apresentavam a dimensão de $8 \mathrm{~m}^{3}(2 \mathrm{~m} \times 2 \mathrm{~m} \times 2 \mathrm{~m})$ e foram instalados em área aberta sem vegetação, anexa ao prédio do LEE/CEIB. No período de 25/01 a 24/02/2006, 20 casais de C. capitata com 2 a 3 dias de idade e 20 casais de $A$. fraterculus com 1 a 3 dias foram liberados no interior dos gaiolóes a cada início do período de exposiçấo. No centro superior de cada gaiolão foi pendurada uma armadilha McPhail plástica transparente contendo $400 \mathrm{~mL}$ de solução atrativa e ao nível do solo foi colocado um vaso contendo uma muda com 8 meses de idade de laranja pera, com aproximadamente $1,0 \mathrm{~m}$ de altura. Ao final de cada período, os adultos capturados foram 
retirados e contados. Segundo dados do Instituto Agronômico de Campinas, no período de condução do experimento a temperatura média variou entre 21,9 e $24,3^{\circ} \mathrm{C}$ e a precipitação acumulada foi $97,1 \mathrm{~mm}$.

O número de fêmeas e machos capturados foi avaliado durante os períodos de exposição dos atrativos no campo $0-2$, $2-4,4-7$ e $7-10$ dias. $\mathrm{O} \mathrm{pH}$ inicial (0 dia) e final (10 dias) foi medido utilizando uma soluçáo de $100 \mathrm{~mL}$ de cada solução atrativa e um pHmetro da marca Alphalab, modelo PA 200.

Foi adotado o delineamento inteiramente casualizado, com teste sem chance de escolha, em esquema fatorial $2 \times 4 \times 4$, sendo duas espécies de mosca, quatro soluçôes atrativas e quatro idades das soluçôes atrativas, com três repetiçóes. Os dados de captura foram submetidos à análise de variância (ANOVA), usando o programa Assistat (versão 7.6 beta). Os valores de captura de cada tratamento foram submetidos ao teste $\mathrm{F}$ e as médias comparadas pelo teste Tukey $(\mathrm{p}<0,05)$.

\section{RESULTADOS E DISCUSSÃO}

Os tratamentos com Milhocina ${ }^{\circledR}+$ Bórax apresentaram aumento dos valores de $\mathrm{pH}$ aos dez dias de exposição em campo, tendo ocorrido o inverso com Bio Anastrepha (Fig. 1). A acidez inicial de Milhocina ${ }^{\circledR}$ diminuiu na medida do aumento da concentração $(<3,81)$. Durante o experimento, os valores de $\mathrm{pH}$ de Milhocina ${ }^{\circledR}$ se mantiveram abaixo da neutralidade e a mistura com bórax permitiu elevar o $\mathrm{pH}$ final até 5,64, regulando a decomposição e liberação acelerada da amônia
(MAzor et al., 1987), além de evitar a putrefação dos insetos capturados (Lopez; Becerril, 1967). Epsky et al. (1994) aumentaram o $\mathrm{pH}$ da proteína hidrolisada (10\%) de 6 para 7 , adicionando bórax (1\%) para captura de Anastrepha suspensa (Loew) na cultura de pitanga Eugenia uniflora L., no período de 7 dias. Para soluçóes atrativas inicialmente alcalinas, os autores obtiveram constância ou leve diminuição do $\mathrm{pH}$, à semelhança do que foi obtido para Bio Anastrepha no presente experimento, ou seja, redução de 7,93 para 7,42, a partir do início até o final do tempo de exposição, respectivamente. Segundo Sharp; Chambers (1983), mudanças no pH de soluçôes nitrogenadas favoreceram a liberação de odores atrativos a adultos de $A$. suspensa.

Utilizando olfatômetro, Mazor et al. (1987) obtiveram melhoria da atratividade de fêmeas de C. capitata com o aumento do $\mathrm{pH}$ de duas proteínas hidrolisadas ácidas, tendo sido comprovado um incremento da atratividade em funçáo do aumento da liberação de amônia. No entanto, o pH ótimo que proporcione o máximo de captura de adultos depende do tipo da proteína hidrolisada (HeAth et al., 1994) e da fonte alcalina adicionada. PAIVA; PARra (2013), em estudo conduzido em pomar de laranja Hamlin, obtiveram 6 vezes mais captura de C. capitata por Milhocina ${ }^{\circledR}(25 \%)+$ bórax com $\mathrm{pH} 8,5$ do que a mesma mistura com pH 4,5.

Embora não seja possível uniformizar, por meio dos protocolos de monitoramento de moscas-das-frutas, o $\mathrm{pH}$ das soluçóes atrativas alimentares utilizadas em armadilhas McPhail, é imprescindível o conhecimento da eficácia dos atrativos comerciais, em função do tempo de exposição, da espécie e da idade dos tefritídeos.

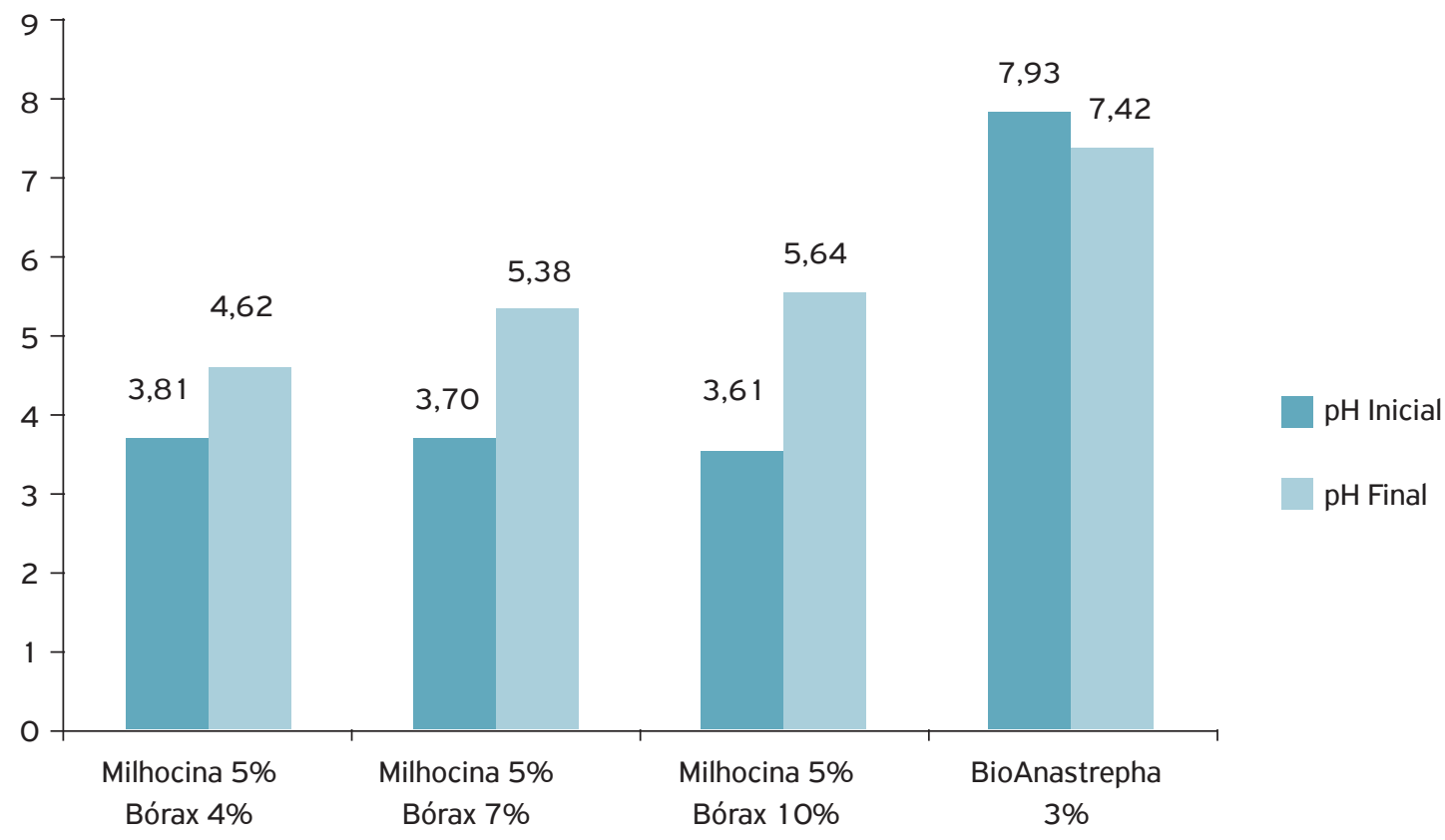

Figura 1. Valores médios de pH no início e final do período de exposição ( 0 a 10 dias) de diferentes atrativos em armadilhas McPhail, em condições de semicampo. Campinas, São Paulo, janeiro a fevereiro de 2006. 
Maior quantidade de adultos de C. capitata foi capturada no atrativo padrão Bio Anastrepha. Houve maiores capturas de machos e de fêmeas + machos de C. capitata do que de A. fraterculus nos tratamentos com Milhocina ${ }^{\circledR}$ (Tabela 1). Para esse atrativo, as capturas de fêmeas foram semelhantes entre as espécies de moscas-das-frutas, provavelmente devido à necessidade premente dos tefritídeos em ingerir compostos nitrogenados para maturação e produção de ovos (HAGEN; Finney, 1950; Bateman, 1972). Bio Anastrepha capturou número semelhante de indivíduos de ambas as espécies, independentemente do sexo e mesmo na somatória de fêmeas e machos (Tabela 1).

Maiores capturas de fêmeas dos tefritídeos testados foram obtidas por Milhocina ${ }^{\circledR}+$ bórax $4 \%$ e pelo padrão Bio Anastrepha até sete dias de exposição dos atrativos (Tabela 1), enquanto que para machos essa eficácia equivalente foi obtida somente até os quatro dias de exposição. Esse fato demonstrou que o aumento do $\mathrm{pH}$ da soluçáa, proporcionado pela adição de Bórax a 4\%, melhorou a atratividade da proteína hidrolisada Milhocina ${ }^{\circledR}$. Bio Anastrepha capturou mais indivíduos (fêmeas + machos) de C. capitata ou de A. fraterculus que as misturas de Milhocina ${ }^{\circledR}$ e Bórax (Tabela 1), sendo que essa mistura a 7 e $10 \%$ interferiu negativamente na atratividade das moscas-das-frutas avaliadas.

As soluçôes de Milhocina ${ }^{\circledR}+$ Bórax e Bio Anastrepha capturaram quantidades semelhantes de fêmeas (Tabela 2), machos (Tabela 3) e fêmeas + machos (Tabela 4) de C. capitata nas idades dos atrativos de $0-2$ e $2-4$ dias. Milhocina ${ }^{\circledR}$ + Bórax 7\% capturou mais fêmeas (Tabela 2) e fêmeas + machos (Tabela 4) de A. fraterculus com $2-4$ dias de exposição. Em geral, no período de $2-4$ dias de exposição, houve um aumento da atratividade das soluçóes proteicas para fêmeas e machos de C. capitata e A. fraterculus (Figs. 2 e 3). Nos períodos de exposição subsequentes houve acentuada

Tabela 1. Valores médios de fêmeas, machos e totais de Ceratitis capitata e de Anastrepha fraterculus capturados por armadilhas McPhail contendo diferentes atrativos alimentares, mantidas em gaiolões de campo durante quatro períodos de exposição. Campinas, São Paulo, janeiro a fevereiro de 2006.

\begin{tabular}{|c|c|c|c|c|}
\hline & \multicolumn{4}{|c|}{ Atrativo } \\
\hline & $\begin{array}{c}\text { Milhocina }{ }^{\circledR} 5 \%+ \\
\text { Bórax } 4 \%\end{array}$ & $\begin{array}{c}\text { Milhocina }{ }^{\circledR} 5 \%+ \\
\text { Bórax } 7 \%\end{array}$ & $\begin{array}{c}\text { Milhocina }{ }^{\circledR} 5 \%+ \\
\text { Bórax } 10 \%\end{array}$ & Bio Anastrepha 3\% \\
\hline Espécies & & Fêmeas & & \\
\hline Ceratitis capitata & $10,1 \mathrm{aA}$ & $6,2 \mathrm{aB}$ & $5,7 \mathrm{aB}$ & $11,7 \mathrm{aA}$ \\
\hline Anastrepha fraterculus & $9,7 \mathrm{aB}$ & $6,2 \mathrm{aC}$ & $4,7 \mathrm{aC}$ & $12,7 \mathrm{aA}$ \\
\hline \multicolumn{5}{|l|}{ Idade do atrativo } \\
\hline $0-2$ dias & $13,5 \mathrm{aA}$ & $9,2 \mathrm{aB}$ & $8,3 \mathrm{aB}$ & $14,3 \mathrm{bA}$ \\
\hline $2-4$ dias & $15,5 a A$ & $9,5 \mathrm{aB}$ & $6,8 a b B$ & $17,5 \mathrm{aA}$ \\
\hline $4-7$ dias & 8,ObA & $4,8 b B$ & $4,3 \mathrm{bcB}$ & $10,7 c A$ \\
\hline $7-10$ dias & $2,5 c B$ & $1,3 c B$ & $1,3 c B$ & $6,5 \mathrm{dA}$ \\
\hline \multicolumn{5}{|c|}{ Machos } \\
\hline Ceratitis capitata & $11,2 \mathrm{aA}$ & $7,3 \mathrm{aB}$ & $7,4 \mathrm{aB}$ & $12,8 \mathrm{aA}$ \\
\hline Anastrepha fraterculus & $8,2 b B$ & $5, \mathrm{ObC}$ & $5, \mathrm{ObC}$ & $12,0 \mathrm{aA}$ \\
\hline $0-2$ dias & $14,2 \mathrm{aA}$ & 7.8abB & $8,7 \mathrm{aB}$ & $14,8 a b A$ \\
\hline $2-4$ dias & $15,2 a A$ & $10,0 a B$ & $11, \mathrm{OaB}$ & $18,0 a A$ \\
\hline $4-7$ dias & $7, \mathrm{ObB}$ & $6,2 \mathrm{bB}$ & $3,8 b B$ & $12,2 \mathrm{bA}$ \\
\hline $7-10$ dias & $2,5 \mathrm{cAB}$ & $0,7 c B$ & $1,3 \mathrm{bAB}$ & $4,7 \mathrm{cA}$ \\
\hline \multicolumn{5}{|c|}{ Totais (machos + fêmeas) } \\
\hline Ceratitis capitata & $21,2 \mathrm{aB}$ & $13,3 \mathrm{aC}$ & $12,8 \mathrm{aC}$ & $24,6 a A$ \\
\hline Anastrepha fraterculus & $17,9 \mathrm{bB}$ & $11,2 b C$ & $9,7 b c$ & $24,7 a A$ \\
\hline $0-2$ dias & $27,7 a A$ & $16,5 \mathrm{aB}$ & $16,5 \mathrm{aB}$ & $29,2 \mathrm{bA}$ \\
\hline $2-4$ dias & $30,7 \mathrm{aB}$ & $19,5 \mathrm{aC}$ & $17,8 \mathrm{aC}$ & $35,5 \mathrm{aA}$ \\
\hline $4-7$ dias & $15, \mathrm{ObB}$ & $11, \mathrm{ObC}$ & $8,2 \mathrm{BC}$ & $22,8 \mathrm{cA}$ \\
\hline $7-10$ dias & $5, \mathrm{OcB}$ & $2, \mathrm{OcB}$ & $2,7 \mathrm{cB}$ & $11,2 \mathrm{dA}$ \\
\hline
\end{tabular}

Médias seguidas pela mesma letra minúscula na coluna e maiúscula na linha dentro de uma mesma variável não diferem entre si pelo teste de Tukey a $5 \%$ de probabilidade. 
Tabela 2. Valores médios de fêmeas de Ceratitis capitata e de Anastrepha fraterculus capturados por armadilhas McPhail contendo diferentes atrativos alimentares, mantidas em gaiolões de campo durante quatro idades dos atrativos. Campinas, São Paulo, janeiro a fevereiro, 2006.

\begin{tabular}{|c|c|c|c|c|}
\hline & \multicolumn{4}{|c|}{ Atrativo } \\
\hline & $\begin{array}{c}\text { Milhocina }{ }^{\circledR} 5 \%+ \\
\text { Bórax } 4 \%\end{array}$ & $\begin{array}{c}\text { Milhocina }{ }^{\circledR} 5 \%+ \\
\text { Bórax } 7 \%\end{array}$ & $\begin{array}{c}\text { Milhocina }{ }^{\circledR} 5 \%+ \\
\text { Bórax } 10 \%\end{array}$ & Bio Anastrepha 3\% \\
\hline \multicolumn{5}{|l|}{ Espécie } \\
\hline Cc (O - 2 dias) & $13,3 a b A$ & $8,7 \mathrm{bcB}$ & $13,7 \mathrm{abA}$ & $8,0 \mathrm{cdB}$ \\
\hline Cc (2 - 4 dias $)$ & $15,3 a A$ & $6,3 b c d B$ & $15,7 a A$ & $7,3 \mathrm{cdB}$ \\
\hline Cc (4 - 7 dias) & $9, \mathrm{ObA}$ & $5,3 \mathrm{cdAB}$ & $7,0 \mathrm{cdAB}$ & 3,3 deB \\
\hline Cc ( $7-10$ dias $)$ & $2,7 \mathrm{cA}$ & $2,3 \mathrm{dA}$ & $2,3 \mathrm{de} A$ & $0,3 e A$ \\
\hline Af (O - 2 dias) & 10,3abB & $11,3 \mathrm{bB}$ & $8,0 \mathrm{cB}$ & $17,3 a A$ \\
\hline Af ( $2-4$ dias) & $10,0 b B$ & $18,3 a A$ & $9, \mathrm{ObcB}$ & $16,7 \mathrm{abA}$ \\
\hline Af ( $4-7$ dias) & $3,3 c \mathrm{C}$ & $9,7 \mathrm{bcAB}$ & $6,3 \mathrm{cdeBC}$ & $11,7 \mathrm{bcA}$ \\
\hline Af ( $7-10$ dias) & $1,3 \mathrm{cB}$ & $7,7 \mathrm{bcA}$ & $1,3 e B$ & $5,3 \mathrm{de} A \mathrm{~B}$ \\
\hline Dms para colunas & 5,26 & & & \\
\hline Dms para linhas & 4,44 & & & \\
\hline CV(\%) & 24,5 & & & \\
\hline
\end{tabular}

Cc: Ceratitis capitata; Af: Anastrepha fraterculus; médias seguidas pela mesma letra minúscula na coluna e maiúscula na linha dentro de uma mesma variável não diferem entre si pelo teste de Tukey a 5\% de probabilidade; Dms: diferença mínima significativa; CV: coeficiente de variação.

Tabela 3. Valores médios de machos de Ceratitis capitata e de Anastrepha fraterculus capturados por armadilhas McPhail contendo diferentes atrativos alimentares, mantidas em gaiolões de campo durante quatro idades dos atrativos. Campinas, São Paulo, janeiro a fevereiro, 2006.

\begin{tabular}{|c|c|c|c|c|}
\hline & \multicolumn{4}{|c|}{ Atrativo } \\
\hline & $\begin{array}{c}\text { Milhocina }{ }^{\circledR} 5 \%+ \\
\text { Bórax } 4 \%\end{array}$ & $\begin{array}{c}\text { Milhocina }{ }^{\circledR} 5 \%+ \\
\text { Bórax } 7 \%\end{array}$ & $\begin{array}{c}\text { Milhocina }{ }^{\circledR} 5 \%+ \\
\text { Bórax } 10 \%\end{array}$ & Bio Anastrepha 3\% \\
\hline \multicolumn{5}{|l|}{ Espécie } \\
\hline $\mathrm{Cc}(\mathrm{O}-2$ dias $)$ & $15,3 a b A$ & $11,3 \mathrm{cA}$ & $13,0 a A$ & $6,0 \mathrm{cdeB}$ \\
\hline Cc (2- 4 dias $)$ & $18,3 a A$ & $13,0 a b c B$ & $12,0 \mathrm{abB}$ & $9, \mathrm{ObcdB}$ \\
\hline Cc (4 - 7 dias) & $7,7 \mathrm{cdA}$ & $3,7 \mathrm{dA}$ & $6,3 \mathrm{bcdA}$ & 4,OdeA \\
\hline Cc (7 - 10 dias $)$ & $3,3 \mathrm{deA}$ & $1,7 \mathrm{dA}$ & $1,7 \mathrm{deA}$ & 1, OeA \\
\hline Af $(0-2$ dias $)$ & $7,7 \mathrm{cdB}$ & 18,OabA & $8,0 a b c B$ & $11,7 a b c B$ \\
\hline Af ( $2-4$ dias $)$ & $11, \mathrm{ObcB}$ & $18,3 a A$ & 9,OabcB & $17,7 \mathrm{aA}$ \\
\hline Af (4 - 7 dias) & $9,3 \mathrm{bcdA}$ & $12, \mathrm{ObcA}$ & $3,0 \mathrm{cdeB}$ & $12,3 a b A$ \\
\hline Af (7 - 10 dias) & $1,3 \mathrm{e} A \mathrm{~B}$ & 3,OdAB & O,OeB & $6,3 \mathrm{bcde} A$ \\
\hline Dms para colunas & 6,21 & & & \\
\hline Dms para linhas & 5,23 & & & \\
\hline CV(\%) & 28,1 & & & \\
\hline
\end{tabular}

Cc: Ceratitis capitata; Af: Anastrepha fraterculus; médias seguidas pela mesma letra minúscula na coluna e maiúscula na linha dentro de uma mesma variável não diferem entre si pelo teste de Tukey a 5\% de probabilidade; Dms: diferença mínima significativa; CV: coeficiente de variação.

queda na capacidade atrativa das soluçóes. Com algumas exceções, as capturas de ambas as espécies de moscas-das-frutas no período de 7 - 10 dias foram significativamente inferiores àquelas capturas obtidas nas demais idades dos atrativos (Tabelas 2 a 4).
No período de 7 - 10 dias de exposição, a captura de fêmeas e machos por Milhocina ${ }^{\circledR}$ foi $93 \%$ menor, em comparação com o período de $2-4$ dias. Esses resultados estão de acordo com os apresentados por Ros et al. (2002), que propuseram a troca dos atrativos alimentares à base de proteína 
Tabela 4. Valores médios de fêmeas + machos de Ceratitis capitata e de Anastrepha fraterculus capturados por armadilhas McPhail contendo diferentes atrativos alimentares, mantidas em gaiolões de campo durante quatro idades dos atrativos. Campinas, São Paulo, janeiro a fevereiro, 2006.

\begin{tabular}{|c|c|c|c|c|}
\hline & & Atr & & \\
\hline & $\begin{array}{c}\text { Milhocina }{ }^{\circledR} 5 \%+ \\
\text { Bórax } 4 \%\end{array}$ & $\begin{array}{c}\text { Milhocina }^{\circledR} 5 \%+ \\
\text { Bórax } 7 \%\end{array}$ & $\begin{array}{c}\text { Milhocina }{ }^{\circledR} 5 \%+ \\
\text { Bórax } 10 \%\end{array}$ & Bio Anastrepha $3 \%$ \\
\hline Espécie & & & & \\
\hline Cc $(0-2$ dias $)$ & $28,7 \mathrm{aA}$ & $19, \mathrm{OcB}$ & $26,7 \mathrm{aA}$ & $14, \mathrm{OcC}$ \\
\hline Cc (2 - 4 dias $)$ & $33,7 \mathrm{aA}$ & $19,3 c \mathrm{C}$ & $27,7 \mathrm{aB}$ & $16,3 c C$ \\
\hline Cc (4 - 7 dias) & $16,7 \mathrm{bcA}$ & 9,OdeBC & $13,3 b c A B$ & $7,3 \mathrm{dC}$ \\
\hline Cc (7 - 10 dias $)$ & $6, \mathrm{OdA}$ & $4, \mathrm{OeAB}$ & 4,OdeAB & $1,3 \mathrm{eB}$ \\
\hline Af (O - 2 dias) & $17, \mathrm{ObcB}$ & $29,3 \mathrm{bA}$ & $16, \mathrm{ObB}$ & 29,0abA \\
\hline Af ( $2-4$ dias $)$ & $21, \mathrm{ObB}$ & $36,7 \mathrm{aA}$ & $18, \mathrm{ObB}$ & $34,3 a A$ \\
\hline Af (4- 7 dias) & $12,7 \mathrm{cB}$ & $21,7 \mathrm{cA}$ & $9,3 \mathrm{cdB}$ & $24, \mathrm{ObA}$ \\
\hline Af ( $7-10$ dias $)$ & $2,7 \mathrm{~dB}$ & $10,7 \mathrm{dA}$ & $1,3 \mathrm{eB}$ & $11,7 \mathrm{cdA}$ \\
\hline Dms para colunas & 5,45 & & & \\
\hline Dms para linhas & 4,60 & & & \\
\hline CV(\%) & 12,6 & & & \\
\hline
\end{tabular}

Cc: Ceratitis capitata; Af: Anastrepha fraterculus; médias seguidas pela mesma letra minúscula na coluna e maiúscula na linha dentro de uma mesma variável não diferem entre si pelo teste de Tukey a 5\% de probabilidade; Dms: diferença mínima significativa; CV: coeficiente de variação.
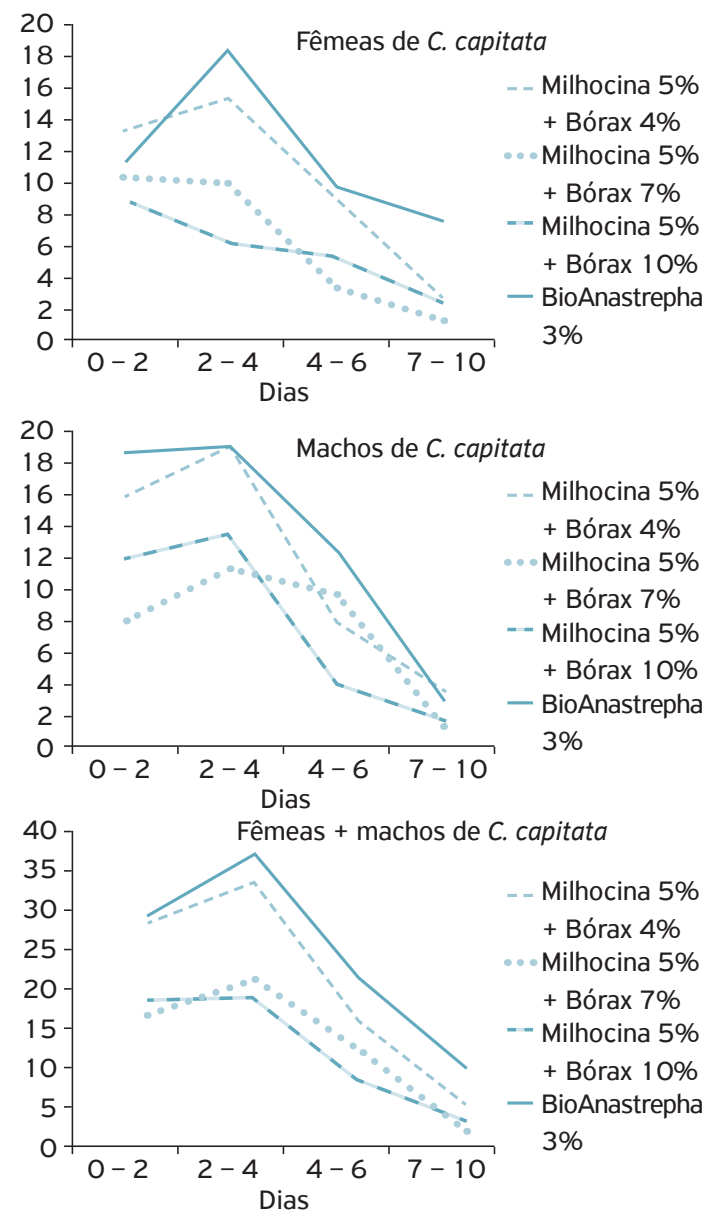

Figura 2. Número médio de adultos de C. capitata capturados por armadilhas McPhail, contendo diferentes atraentes alimentares durante quatro períodos de exposição, em gaiolões de campo. Campinas, São Paulo, janeiro a fevereiro, 2006.
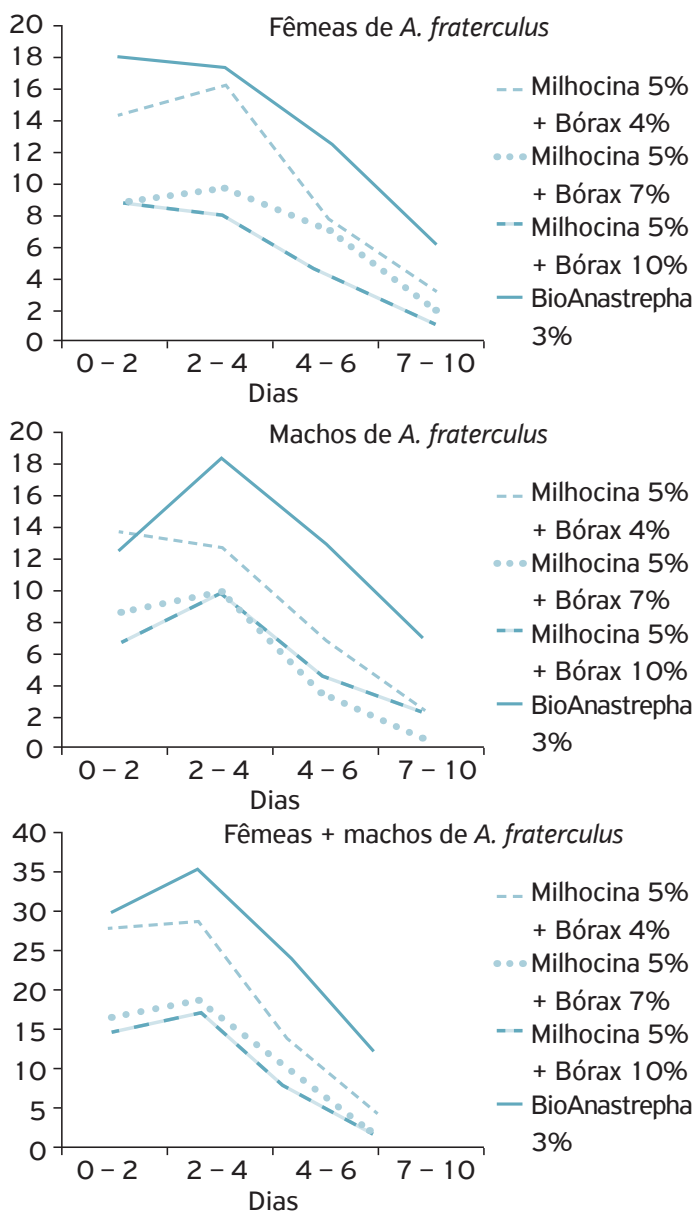

Figura 3. Número médio de adultos de $A$. fraterculus capturados por armadilhas McPhail, contendo diferentes atraentes alimentares durante quatro períodos de exposição, em gaiolões de campo. Campinas, São Paulo, janeiro a fevereiro, 2006. 
hidrolisada em períodos não superiores a sete dias, na época de verão, ocasião em que deverá ser realizada a contagem dos espécimes capturados (RAGA, 2006). Portanto, existem diferenças significativas na eficácia dos atrativos alimentares durante o tempo de exposição de armadilhas McPhail, independentemente das variáveis biológicas e ambientais envolvidas, como a migração das espécies (movimentos dispersivos), preferência e diversidade hospedeira, idade de adultos e tamanho da população dominante no local (Bateman, 1972).

Milhocina ${ }^{\circledR}+$ Bórax $4 \%$ capturou mais fêmeas de $C$. capitata do que o padrão Bio Anastrepha, aos $0-2,2-4 \mathrm{e}$ $4-7$ dias de idade dos atrativos, tendo ocorrido o inverso para fêmeas de $A$. fraterculus (Tabela 2). Esse padrão de captura observado para fêmeas se confirmou quando se analisou a soma de capturas de ambos os sexos (Tabela 4).

Baseando-se nas curvas de captura obtidas por diferentes atrativos (Figs. 2 e 3), constatou-se que os machos jovens de Tephritidae também buscam atrativos alimentares. BioAnastrepha, aos 2-4 dias de idade, capturou número

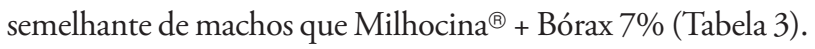
Para as três idades dos atrativos, esses tratamentos foram semelhantes na captura de fêmeas + machos de $A$. fraterculus (Tabela 4).

A escolha adequada do atraente é fundamental para o conhecimento da dinâmica populacional de moscas-das-frutas por proporcionar uma definiçãa, no tempo e no espaço, das medidas de manejo dessas pragas (Raga et al., 2006). Por isso, em função da dominância da espécie de moscas-das-frutas observada em cada região produtora, deverá se optar pelo atrativo mais adequado para se obter um monitoramento populacional confiável. O desenvolvimento de melhores atrativos é fundamental para os sistemas de monitoramento e também para o controle denominado "atrai e mata" (attract and kill) ou de coleta massal de moscas-das-frutas com armadilhas (mass trapping), possibilitando, nesse caso, reduzir a densidade de armadilhas em campo.

\section{CONCLUSÕES}

A elevaçâo do $\mathrm{pH}$, com adição de Bórax, melhora o poder atrativo da proteína hidrolisada Milhocina ${ }^{\circledR}$. Misturas de Milhocina ${ }^{\circledR}$ e Bórax, além de Bio Anastrepha, atraem fêmeas e machos de C. capitata e A. fraterculus. Bio Anastrepha a 3\% $(\mathrm{v} / \mathrm{v})$ é superior a Milhocina ${ }^{\circledR}$ e suas misturas na atratividade de C. capitata e A. fraterculus. A partir de sete dias de exposição a campo, soluções de proteína hidrolisada apresentam redução significativa na atratividade de tefritídeos.

\section{AGRADECIMENTOS}

Ao Sr. Gabriel Buratto da Silva pelo auxílio nas atividades de laboratório e campo e à Fundação de Amparo à Pesquisa do Estado de São Paulo (FAPESP) pela bolsa concedida ao segundo autor.

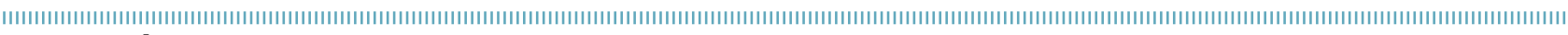
REFERÊNCIAS

ALUJA, M.; CABRERA, M.; GUILLÉN, J.; CELEDONIO, H.; AYORA, F. Behaviour of Anastrepha ludens, A. obliqua, e A. serpentina (Diptera: Tephritidae) on a wild mango tree (Mangifera indica) harbouting three MacPhail traps. Insect Science and its Application, Nairobi, v.10, n.3, p. 309-318, 1989.

ALUJA, M. Bionomics and management of Anastrepha. Annual Review of Entomology, Palo Alto, v.39, p.155-178, 1994.

BATEMAN, M.A. The ecology of fruit flies. Annual Review of Entomology, Palo Alto, v.17, p. 493-518, 1972.

EPSKY, N.D.; HEATH, R.R.; HOLLER, T.C.; HARRIS, D.L.; MULLINS, T. Corn steepwater as protein bait for Anastrepha suspensa (Diptera: Tephritidae). Environmental Entomology, Lanham, v.23, n.4, p.827-831, 1994.
HAGEN, K.S.; FINNEY, G.L. A food supplement for effectively increasing the fecundity of certain tephritid species. Journal of Economic Entomology, Washington, v.43, n.5, p. 735, 1950.

JANG, E.B.; HOLLER, T.C.; MOSES, A.L.; SALVATO, M.H.; FRASER, $S$. Evaluation of a single-matrix food attractant tephritid fruit fly bait dispenser for use in federal trap detection programs. Proceedings of Hawaiian Entomological Society, v.39, p.18, 2007.

HEATH, R.R.; EPSKY, N.D.; BLOEM, S.; BLOEM, K.; ACAJABON, F.; GUZMAN, A.; CHAMBERS, D. pH effect on the attractiveness of a corn hydrolysate to the Mediterranean fruit fly and several Anastrepha species (Diptera: Tephritidae). Journal of Economic Entomology, College Park, v.87, n.4, p.1008-1013, 1994. 
HEATH, R.R.; VAZQUEZ, A.; SCHNELL, E.Q.; VILLAREAL, J.; KENDRA, P.E.; EPSKY, N.D. Dynamics of $\mathrm{pH}$ modification of an acidic protein bait used for tropical fruit flies (Diptera: Tephritidae). Journal of Economic Entomology, Lanham, v. 102 , n.6, p.2371-2376, 2009

LOPEZ, F. D.; BECERRIL, O. H. Sodium borate inhibits decomposition of two protein hydrolysates attractive to the Mexican fruit fly. Journal of Economic Entomology, Laham, v. 60, n.1, p. 137-140, 1967.

LOPEZ, F; STEINER, L.F.; HOLBROOK, F.R. A new yeast hydrolysateborax bait for trapping the Caribbean fruit fly. Journal of Economic Entomology, College Park, v.64, n.6, p.1541-1543, 1971.

MALO, E.A. Effect of bait decomposition time on capture of Anastrepha fruit flies. Florida Entomologist, v.75 n.2, p. 272274, 1992.

MAZOR, M.; GOTHILF, S; GALUN, R. The role of ammonia in the attraction of females of the Mediterranean fruit fly to protein hydrolysate baits. Entomologia Experimentalis et Applicata, Amsterdam, v.43, n.1, p.25-29, 1987.

MAZOR, M. Competitiveness of fertilizers with proteinaceous baits applied in Mediterranean fruit fly, Ceratitis capitata Wied. (Diptera: Tephritidae) control. Crop Protection, v.28, n.4, p. 314318, 2009.

MONTES, S.M.N.M.; RAGA, A. Eficácia de atrativos para monitoramento de Ceratitis capitata (Diptera: Tephritidae) em pomar de citros. Arquivos do Instituto Biológico, São Paulo, v.73, n.3, p.317-323, 2006.

NASCIMENTO, A.S.; CARVALHO, R.S.; MALAVASI, A. Monitoramento populacional. In: MALAVASI, A.; ZUCCHI, R.A. (eds.). Moscas-dasfrutas de importância econômica no Brasil. Ribeirão Preto: Editora Holos, 2000. p.109-112.

PAIVA, P.E.B.; PARRA, J.R.P. Hidrogenionic potential ( $\mathrm{pH}$ ) of the attractant, trap density and control threshold for Ceratitis capitato (Diptera: Tephritidae) on Hamlin oranges in São Paulo Central region, Brazil. Revista Brasileira de Fruticultura, Jaboticabal, v.35 n.2, p.464-470, 2013

PIÑERO, J.; ALUJA, M.; VÁZQUEZ, A.; EQUIHUA, M.; VARÓN, J. HUMAN urine and chicken feces as fruit fly (Diptera: Tephritidae) attractants for resource-poor fruit growers. Journal of Economic Entomology, Lanham, v.96, n.2, p.334-340, 2003.

RAGA, A.; SATO, M.E.; POTENZA, M.R.; GIORDANO, R.B.P.; SZULAK, C.; SUPLICY FILHO, N. Uso da radiação gama para desinfestação de mangas em relação a larvas de Ceratitis capitata (Wied., 1824),
Anastrepha fraterculus (Wied., 1830) e Anastrepha obliqua (Macquart, 1835). Ecossistema, Espírito Santo do Pinhal, v.18, p.45-55, 1993.

RAGA, A., YASUOKA, S.T.; AMORIM, E.O.; SATO, M.E.; SUPLICY FILHO, N.; FARIA, J.T. Sensibilidade de ovos de Ceratitis capitata (Wied., 1824) irradiados em dieta artificial e em frutos de manga (Mangifera indica L.). Scientia Agricola, Piracicaba, v.53, n.1, p. $114-118,1996$.

RAGA A.; PRESTES, D.A.O.; SOUZA-FILHO, M.F.; SATO, M.E., SILOTO, R.C.; GUIMARÃES, J. A.; ZUCCHI, R. A. Fruit fly (Diptera: Tephritoidea) infestation in citrus in the State of São Paulo, Brazil. Neotropical Entomology, Londrina, v. 33, n. 1, p. 85-89, 2004.

RAGA, A. Incidência, monitoramento e controle de moscas-dasfrutas na citricultura paulista. Laranja, Cordeirópolis, v.26, n2, p.307-322, 2005

RAGA, A.; MACHADO, R.A.; DINARDO, W; STRIKIS, P.C. Eficácia de atrativos alimentares na captura de mosca-das-frutas em pomar de citrus. Bragantia, Campinas, v.65, n.2, p.337-345, 2006.

RAGA, A.; SOUZA-FILHO, M.F.; MACHADO, R.A.; SATO, M.E.; SILOTO, R.C. Host Ranges and infestation indices of fruit flies (Tephritidae) and lance flies (Lonchaeidae) in São Paulo State, Brazil. Florida Entomologist, Lutz, v. 94, n.4, p. 787-794, 2011.

ROS, J.P.; WONG, E.; OLIVERO, J., CASTILLO, E. Mejora de los mosqueros, atrayentes y sistemas de retención contra la mosca mediterránea de la fruta Ceratitis capitata Wied. Como hacer de la técnica del trampeo masivo una Buena herramienta para controlar esta plaga. Boletin de Sanidad Vegetaly Plagas, Madrid, v.28, n.4, p.591-598, 2002

SALLES, L.A. Efeito do envelhecimento e da decomposição do atrativo na captura de adultos de Anastrepha fraterculus (Wied.) (Diptera: Tephritidae). Revista Brasileira de Agrociência, v.5. n. 2, p. 147-148, 1999

SHARP, J.L.; CHAMBERS, D.L. Aggregation response of Anastrepha suspensa (Diptera: Tephritidae) to proteins and amino acids. Environmental Entomology, College Park, v.12, n.3, p.923928, 1983.

THOMAS, D.B.; HOLLER, T.C.; HEATH, R.R.; SALINAS, E.J.; MOSES, A.L. Trap-lure combinations for surveillance of Anastrepha fruit flies (Diptera: Tephritidae). Florida Entomologist, Lutz, v.84, n.3, p.344-351, 2001

VILLAR, L.; CRUZ, M.C.M.; MOREIRA, R.A.; CURI, P.N. Atrativos alimentares na flutuação populacional de moscas-das-frutas e abelha irapuá. Scientia Agraria Paranaensis, Marechal Cândido Rondon, v.9, n.3, p.67-73, 2010. 